\title{
Paradojas de la Industrialización Mexicana: Del desarrollo estabilizador a la reconversión forzada
}

\author{
Emilio Gerardo Arriaga Álvarez \\ Facultad de Ciencias Políticas y Administración Pública UAEM
}

\section{Presentación}

El objetivo del presente trabajo es el acercamiento a las paradojas de la industrialización mexicanaa partirdel modelodesustitución deimportaciones y hasta la reconversión industrial y la imposición del denominado modelo neoliberal.

La primera parte, es una revisión histórico-económica del avance del modelo industrializador y sus límites. La segunda parte, intenta algunas explicaciones al proceso de reconversión, a partir de las modificaciones al modelo de desarrollo. En la tercera parte, intentamos un análisis de las repercusiones de la globalización en la industria (particularmente en la mexicana) y las paradojas que se presentan como consecuencia de la instrumentación de las políticas monetaristas. Finalmente, presentamos algunas conclusiones parciales respecto de los fenómenos abordados.

\section{PARADOJA 1: 1940-1970: La ęrevolución? industrial mexicana}

En el verano de 1982, el Secretario de Hacienda de México, Jesús Silva Herzog, declaró una moratoria al pago de la deuda externa de su gobierno. De ahí a la fecha, la crisis económica de México se agravó paulatinamente. En 1987, por ejemplo, hacía ya cinco años que el crecimiento económico nacional, se encontraba en situación de estancamiento. En términos per capita, había disminuido a un ritmo de poco más de $2.5 \%$ anual. (Haber, 1992: 15-16)

La espiral descendente de la economía, deterioró profundamente los salarios y el nivel de vida de la población en general.

Entre 1982 y 1987, los salarios reales, disminuyeron en aproximadamente $50 \%$, con el consecuente perjuicio en los niveles de nutrición, vivienda y otras necesidades básicas. Alimentos que las familias mexicanas alguna vez 
consideraron esenciales, se convirtieron en artículos de lujo. Una gran parte de la planta industrial del país se encontraba ociosa debido a que la demanda interna, no era lo suficientemente alta para permitir su operación.

El valor del peso mexicano, que durante mucho tiempo fue considerado, como una de las divisas más estables del mundo, cayó estrepitosamente. A principios de 1982 se cambiaba a 22.50 por dólar ya 148.00 para fines del mismo año, fecha a partir de la cual, su descenso fue ininterrumpido, a razón de una tasa aproximada del 50\% anual. En el verano de 1987, el dólar valía ya 1,500.00 pesos. \{Haber, 1992: 16-17)

Por otro lado, la administración del petróleo, producto que el entonces presidente José López Portillo (1976-1982) postulaba como la puerta por la que México ingresaría al mundo desarrollado, resultó un fracaso absoluto. Se gastaba casi la misma cantidad de divisas, tanto en la importación de bienes de capital y tecnología, como en la exploración e inversiones en infraestructura, que lo que se obtenía en ingresos petroleros. Con la grave caída en lo precios del petróleo y sin visos de mejora alguna, de las condiciones del mercado a corto plazo, era sumamente dudoso que México pudiera resolver su crisis económica, mediante la exportación de petróleo.

Lo que puede resultar sorprendente, es que en 1979, apenas tres años antes de aquella declaración de Silva Herzog, tanto la prensa como las publicaciones especializadas, aseguraban que la economía mexicana, se encontraba en uno de sus mejores momentos. Con cada nuevo préstamo, y con cada nuevo aumento en los precios mundiales del petróleo, el horizonte de México, parecía más prometedor. Según las opiniones prevalecientes, el crecimiento económico sostenido, disminuiría la dependencia del país con respecto de EU y prácticamente lo colocaría al mismo nivel.

Antes de la crisis de 1982, todo parecía indicar, que con la combinación de petróleo y créditos externos, podría lograrse cualquier cosa. Sin embargo, no es de asombrarse que "El milagro" mexicano, se derrumbara tan rápidamente, ya que lo cierto es, que la economía mexicana, no era saludable. Los propios créditos externos y las abultadas exportaciones de petróleo, que para la mayoría de los analistas representaban sistemas positivos, en realidad eran indicadores de que la economía se encontraba en graves dificultades.

El crecimiento del país, llegó a depender casi absolutamente, de los rubros préstamos y exportación petrolera. En 1982, 75\% de esos ingresos totales por exportación, provenía del petróleo. (Haber, 1992: 16-17)

¿Cómo se llegó a esta grave situación? ¿Cuáles fueron los antecedentes económico políticos de la crisis? 


\section{1.- La Industrialización para el Crecimiento. Génesis del milagro}

El desarrollo industrial de México, fue un proceso guiado directamente por políticas gubernamentales hacia dicho sector. En la posibilidad de instrumentar dichas políticas confluyen, a partir de la década de los años cuarenta, una serie de elementos tanto externos como internos. Entre los primeros, la segunda guerra mundial fue la de mayor importancia, pues permitió un intervalo de varios años, en los que la industria mexicana maduró, sin la presión de la competencia externa. Sin embargo, el aprovechamiento de dichas condiciones, favorables ellas a nivel internacional, sólo fue posible, como resultado de los cambios institucionales, que se dieron en las dos décadas anteriores, tanto en el orden político económico, como en la esfera de lo social.

El proceso moderno de crecimiento industrial, se inició en condiciones particularmente favorables para el país, en muchos aspectos. Ello contribuyó, en buena medida, en la posibilidad de conciliar los conflictos de intereses y percepciones, entre los diversos grupos sociales involucrados. También, que se hayan adoptado políticas, que a la vuelta de unos años, representarían serios obstáculos, para el crecimiento acelerado de la industria y sus posibilidades de exportación. De ahí también, tal vez, las expectativas demasiado ambiciosas, que se fincaban en el proceso de industrialización. (Trejo, 1987: 15)

Lo anterior es una de las explicaciones, a la dificultad para la adopción de políticas flexibles, a diferencia de otros países de industrialización reciente, que iniciaron dicho proceso una década más tarde, con respecto de México; tales como Corea o Taiwán; y que por lo tanto, debieron enfrentar, condiciones difíciles desde el principio.

En México “... siempre existió, un amplio margen para la ineficiencia. Ello permea en la actualidad, todo el aparato económico y dificulta considerablemente, el desarrollo de sectores de alta eficiencia, con capacidad de incrementar rápidamente sus exportaciones." (Trejo, 1987: 15)

En las primeras etapas del desarrollo industrial, se cumplió en un grado relativamente alto, el requerimiento de un amplio consenso social, alrededor de las políticas de industrialización y ello contribuyó a garantizar su éxito. Sin embargo; a través del tiempo, dicho consenso se erosionó gradualmente, pues la situación de importaciones, no dio los resultados esperados en términos de empleo, bienestar para los grupos mayoritarios e independencia económica nacional.

A partir de la década de los sesenta, empieza a expresarse más abiertamente el desencanto, a la vez, que se presenta un aumento de la conciencia, 
sobre la magnitud de los problemas no resueltos en nuestra sociedad. Por ejemplo, el problema del empleo y el asunto inacabado de la desigual distribución del ingreso. No se trata de problemas nuevos en la historia de nuestro país. Se trata de la observación de que el simple crecimiento cuantitativo, no sólo no ha sido suficiente históricamente para resolver dichos problemas, sino que el ritmo del crecimiento demográfico, los hace aún mayores en términos absolutos.

Parece lógico, que en las primeras etapas de la industrialización, los beneficios sean tangibles para unos cuantos y la posibilidad de alcanzar esos beneficios, sea muy lejana para los grupos más amplios de la sociedad. Sin embargo, la "promesa del progreso" es importante para unificar criterios y voluntades, alrededor de políticas que, en una u otra forma, implicaban un proceso de concentración de recursos. Así, el reservar el mercado nacional para los productores del país, a través de una política de protección, para la industria nacional frente a la competencia del exterior, implicaba una transferencia real de recursos, de muchos consumidores hacia unos cuantos productores. Dicha transferencia, se trataba de justificar, en términos sociales, en función de la posibilidad, de avanzar hacia un mayor nivel de bienestar para la mayoría de la población, en algún horizonte del tiempo. A este "reto permanente", quiso responder la política industrial desde su inicio.

El problema a resolver desde el principio de las políticas de industrialización, es la vieja idea, de hacer compatibles en un mayor grado, los requerimientos del desarrollo, con las demandas de la población, en particular, la económicamente activa, en constante aumento, es decir: ¿cómo lograr al mismo tiempo, eficiencia y equidad? (Trejo, 1987: 16)

Sin embargo, parece que en la actualidad, esa vieja idea se va mutando y poco a poco es sustituida por la introducción del darvinismo económico social.

\section{2. - Las Etapas del Despegue Industrial}

La evolución de la política de desarrollo industrial, a partir de sus inicios en el periodo inmediatamente posterior a la Segunda Guerra mundial, ha pasado por diferentes etapas. La primera de éstas, se identifica con la sustitución de importaciones de bienes de consumo y en términos generales, abarca el periodo de mediados de los años cuarenta, hasta finales de la década de los cincuenta.

La segunda etapa, de creciente sustitución de bienes de capital e intermedios, comprende hasta fines de los años sesenta. 
La tercera etapa, abarca de 1970, hasta 1982. En cada una de las mismas, el manejo de la política proteccionista, tuvo objetivos y características diferentes. Intentaremos describirlas en términos generales:

En la primera etapa, la protección respecto de la competencia del exterior y el impulso a las manufacturas nacionales, fueron generalizados. El hecho de que el crecimiento de la producción industrial, se haya concentrado preferentemente en los sectores de bienes de consumo, puede atribuirse al deseo de aprovechar las mejores y más evidentes oportunidades de mercado que existían, así como a la política gubernamental relativamente poco selectiva en materia industrial. En aquellas actividades, en las cuáles se identificaba a nivel privado, un potencial de rentabilidad, la política proteccionista era de franco apoyo, por lo que tales actividades crecieron con gran rapidez.

Durante la segunda etapa se observa, un grado mayor de selectividad, con un énfasis en la producción de bienes intermedios y de capital. Sin embargo, el esquema de protección siguió siendo el mismo. Es decir, se continuó con el cierre de la frontera, a las importaciones que competían con la producción nacional, con la sujeción de los productos seleccionados, al requisito del permiso previo de importación (que por lo general no se concedía) y con la concesión, de un tratamiento fiscal favorable, a la fabricación nacional. (Trejo, 1987: 17)

En consecuencia, por el afán de apoyar el desarrollo de todo tipo de nuevas actividades, gradualmente se incrementó el uso del permiso previo de importación, en preferencia al arancel. Ello tuvo varios efectos negativos. No solamente perdió transparencia la protección, sino que el fisco dejó de percibir ingresos, que de otra forma, habría recibido por concepto de derechos de importación. Al mismo tiempo, se perdió la relación entre los precios internos y los internacionales y dejó de manejarse el criterio de temporalidad limitada de la protección, que de alguna forma había estado presente, en los inicios de este proceso, aun cuando no se cumpliera.

El ordenamiento básico en que se sustentaron estas políticas fue, en todo el periodo: la Ley de Industrias Nuevas y Necesarias. (Trejo, 1987: 17)

Como resultado de este esquema, el grado de protección efectiva, concedida al sector industrial, fue considerablemente mayor del que se aparentaba.

Lo anterior se indica de una manera clara, en estudios efectuados hacia finales de los años sesenta, pero referidos a la estructura interindustrial de la producción para 1960. (Trejo, 1987: 18)

Por otro lado, la importancia de la política proteccionista, no es solamente cuantitativa. Más allá de ello, la estructura de la misma, reflejada en los niveles de protección efectiva, tuvo casi de manera inevitable, un sesgo hacia la producción de bienes de consumo. A pesar de que en los sesenta, se 
reconocía el nivel excesivamente elevado de la protección, las políticas de la época, de hecho agravaron el problema, pues se requerían crecientes niveles de protección para alcanzar el objetivo de profundizar la sustitución de importaciones. De tal suerte, que en los años setenta, a pesar de los cambios en el esquema de protección, ésta fue en general, más elevada que en la década anterior. (Trejo, 1987: 18)

En la tercera etapa, a partir de 1970, existe ya una clara conciencia acerca de los problemas del proteccionismo excesivo, el bajo nivel de eficiencia del sector industrial y el déficit creciente en la balanza de pagos.

Sin embargo, durante esta época se generalizó el uso de los subsidios como instrumento de fomento industrial, a la vez que se incrementó el uso del permiso previo para proteger a la industria de la competencia internacional.

A pesar de la creación de instituciones como el IMCE y el CONACYT, y de la concesión de una amplia gama de apoyos a las empresas tales como CEDYS, CEPROFIS, decretos para elaborar la descentralización de la industria, el Decreto para Sociedades De Fomento, etc., no se logró avanzar hacia las metas de mayor eficiencia, competitividad internacional e integración de la industria a los objetivos nacionales de carácter social. Como antes, el sector siguió beneficiándose de una política de concentración de los recursos, financiada costa del resto de la economía y en un grado creciente, de créditos externos. Resulta entonces, que ante la evidencia de agotamiento del modelo de sustitución de importaciones, la necesidad de reconversión se iba haciendo cada vez más, un imperativo.

El difícil contexto internacional, cada vez más dinámico, planteaba retos sumamente complejos para las políticas industriales. Si en el pasado se trataba únicamente, de ampliar las bases productivas de la industria nacional, la interdependencia de la economía del país con respecto del exterior, que en muchos sectores era una dependencia absoluta, obligaba a ser eficientes todos los procesos.

Y por si esto fuera poco, recuperar una trayectoria de crecimiento bajo el peso de una deuda externa no planeada, obligaba al país a generar divisas a un ritmo nunca antes visto, y por ende a transformar el carácter del crecimiento industrial y la relación del sector con el resto de la economía. Resulta entonces válido preguntarse, si es posible conciliar tales imperativos, con las demandas sociales de la población. Al parecer, lo más importante para el Estado, poco tiene que ver con dichas demandas, cuando menos esa es la tendencia. La importancia de las políticas de reconversión, se dirigirán de aquí en adelante, al logro de la eficiencia de los procesos productivos y la atenuación de las desventajas generadas por los efectos negativos del anterior 
modelo, el cual por cierto, encontró de manera paradójica, sus límites en lo que parecían ser sus aspectos más positivos.

\section{PARADOJA 2: La ruptura}

Las condiciones de la industria a nivel mundial, presentan una tendencia a la ruptura a partir de los años sesenta. Centraremos el análisis de este apartado en base al trabajo de Patricia Arrieta Robles: "Reestructuraciones tecnológicas de la economía internacional y algunas de sus implicaciones para el sistema productivo mexicano".

En la mencionada obra se nos indica, que las innovaciones tecnológicas están provocando rupturas a nivel mundial en la industria, sobre todo a partir de los avances en la microelectrónica y en las tecnologías de los ordenadores. El problema que a mi juicio es más importante para este trabajo es: hasta que punto México puede incorporarse, a los avances de las novísimas tecnologías, en condiciones mínimamente adecuadas. Ése es un reto, que la autora muestra a través de su análisis.

La primera afirmación importante es, que la economía mundial, sufre una importante desaceleración a fines de los años sesenta. (Arrieta, 1994: 33)

Las principales manifestaciones de estas rupturas, son a decir de Arrieta: una disminución en la importancia de las industrias química y metalmecánica. "Hay sin embargo, un dato importante, ramas que resisten la caída: la electrónica y material de precisión e incluso una que eleva su ritmo de crecimiento: la electrónica de gran público". (Arrieta, 1994: 35)

Lo anterior, dice la autora, es un dato interesante. Nos indica, no solamente la situación de crisis a nivel mundial, sino una mutación del modo de crecimiento; de una transición entre dos eras industriales y entre dos grandes paradigmas:

1.- La forma de producción puesta en marcha a fines de la Segunda Guerra mundial, basada en el impulso de EU y en la industria del petróleo, electromecánica, química y automotriz; y en el fordismo y taylorismo como organización del trabajo y como las condiciones que representan al viejo modelo.

2.- Una nueva forma de producción que comienza a perfilarse desde los años setenta, en la que la microelectrónica está en la base de nuevos modos de producir; de nuevas formas de organización del trabajo (mas integral); nuevas formas de comercialización de productos (a partir de la creación de nuevos bloques comerciales) y una nueva división internacional del trabajo (a partir de la segmentación internacional de procesos productivos). (Arrieta, 1994: 36-37) 
A estos paradigmas, la autora les denomina también: modelos técnicoeconómicos. Se trata de una transición todavía inacabada.

Por una parte, el modelo que está por agotarse, tiene como una de sus características, "hacer lo mismo, pero mejor". Es de repetición rutinaria con tareas específicas, en cadenas de producción, en base a la medición de tiempos y movimientos. Su producción es masiva. Se trata de productos idénticos en que la maquinaria se amortiza a largo plazo y con un costo que pretende ser mínimo. Las actividades de producción están desasociadas de la administración, de los técnicos, de los vendedores y compradores. Los grandes consorcios, acaparan las empresas ubicadas en todas las ramas de la producción de materias primas e insumos, productos manufacturados, así como su distribución, y comercialización.

El nuevo modelo, el que se perfila por la negación de todo paradigma, se sustenta en la creación y utilización de tecnología que aún no deja ver sus límites. Implanta consecuentemente, esquemas versátiles y flexibles, que responden y se ajustan a un desarrollo científico y tecnológico especialmente dinámico y a la demanda cambiante del mercado. La organización del trabajo es flexible, adecuada a los cambios en los modos de producción. Producciones de naturaleza tal, que permite la elaboración de productos diferenciados, de acuerdo a la demanda. Las actividades tienen un enfoque sistémico, el cual enfatiza la interconexión entre áreas, con el objeto de lograr una mejor integración. (Arrieta, 1994: 37-38-39)

El nuevo modelo, emplea la herramienta novísima por antonomasia: la computadora. Hoy, toda la industria (y tal vez la sociedad) está condicionada por esta poderosa herramienta.

Una situación sociopolítica que se vislumbra como igualmente novísima es que:

"Las ideas no están comprometidas con ninguna limitación territorial. La concentración en grandes núcleos de producción, tiene hoy, menos justificación que nunca. "(Arrieta, 1994:40)

Las nuevas formas de producir, tienen como condición de su éxito, la capacidad para adaptarse a situaciones cambiantes.

Otro punto interesante, es el advenimiento de los sistemas digitales. Éstos, están cambiando el sentido y la concepción del mundo. Los fenómenos son captados ahora, de una manera discreta, es decir, en partículas. Para la industria, representa una revolución en los procesos productivos. Los circuitos electrónicos, realizan todo tipo de trabajos y cálculos numéricos. La microelectrónica está englobando toda una insospechada gama de productos y diseños, que escapan a nuestra posibilidad de listado. 


\section{1.- ¿Adaptación después del rompimiento?}

Surge la pregunta en el seguimiento de Arrieta: ¿en qué medida la economía mexicana, es susceptible de adaptarse al modelo técnico económico que se perfila a nivel mundial?

La autora considera tres elementos para el paso al nuevo modelo y que es considerada por los especialistas, como reestructuración (reconversión) industrial:

1. Modernización de la tecnología, incorporando maquinaria y equipo más avanzado, conjuntamente con el uso de nuevos materiales.

2. Cambios en la organización del trabajo.

3. La modernización de los sistemas de gestión y organización de las empresas.

El impacto que tienen estos elementos, se da básicamente en las empresas transnacionales. Se trata, de una reestructuración polarizante. (Arrieta, 1994: 44)

Las conclusiones respecto de la reestructuración tecnológica, tienen tres efectos principales:

1. Cambios en la inserción en algunas ramas de la estructura productiva, con un importante nivel de exportación e importación. Estas ramas cuentan con ventajas comparativas, tales como avanzadas formas de operación a partir de la automatización, control computarizado etc.

2. El surgimiento de la exportación de manufacturas como una fuerza alternativa de crecimiento industrial.

3. La diversificación de estrategias industriales bien diferenciadas. Industrias de importación, de exportación, domésticas, etc. (según tipologías de la autora). Las tendencias se darán, a partir de las capacidades de cada industria y de la rama en particular.

Pero la tendencia a la diversificación y los cambios, se darán en función (para el caso mexicano) de las prioridades de desarrollo, a partir de la necesidad de elevar la competitividad industrial, adoptando nuevas y mejores tecnologías, en un marco global de modernidad.

\section{PARADOJA 3.- Límites de la innovación: el paro}

El problema de la racionalización y la automatización del trabajo, se topa en la actualidad, con límites que desde el Siglo XIX, se contemplaban. ¿Hasta qué punto puede llegar la racionalización y particularmente la automatización? 
Las estrategias empresariales, pasan en la actualidad, por las nuevas formas de organización del trabajo y por la adopción adaptación de innovaciones tecnológicas.

Sin embargo, estas potencialidades se manifiestan hoy, en su justa dimensión. Se trata de una dimensión destructiva, que rebasa el ámbito de lo meramente económico, para situarse en la esfera de lo sociopolítico. Se trata de una destrucción masiva de puestos de trabajo, producto de la automatización. La racionalización y la automatización, dicen Kern y Schumann, arrastran el virus de la destrucción. Dicho de otra manera:

El paro actual tiene que atribuirse ya en gran parte a las modernas técnicas de automatizacion. Y aún habrá que contar con mayores pérdidas netas de puestos de trabajo en el futuro, cuando las posibilidades de racionalizacibn indicadas acaben de desplegarse por completo. (Kern y Schumann; 1988;5-6)

El texto citado, hace referencia a una situación que se presentaba en Europa. Cabe preguntarse: ¿qué sucederá en México?

Bajo las circunstancias actuales, el horizonte parece muy nublado. Paradójicamente, las tendencias que los autores observan en los usos de la fuerza de trabajo, tienden a aprovechar al máximo las potencialidades de las fuerzas productivas desarrolladas, en mano de obra altamente calificada y con suficiente soberanía profesional.

Otra de las paradojas, que se pueden inferir en una situación de extrema automatización, bajo las condiciones sociopolíticas actuales, es: ¿quién consumirá los productos ofrecidos en el mercado, si las oportunidades de empleo se reducen al máximo? Esto parece que no es realmente un asunto que preocupe a las nuevas élites. Parece que la respuesta llega de manera muy clara.

Veamos:

\section{1.- El nuevo liberalismo ¿mexicano?}

En América Latina y en nuestro país, desde el agotamiento del llamado Estado de Bienestar, se han instrumentado políticas económicas cuyo objetivo principal es cambiar el sistema de acumulación de capital, modificando los esquemas en que dicho proceso se generaba. El nuevo esquema de acumulación se denomina corrientemente como Neoliberalismo.

De hecho, la teoría neoliberal es un conjunto de propuestas de teoría económica, con nombres muy diversos, cuyo punto de acuerdo es estar inspiradas, en buena medida, con las propuestas liberales clásicas del siglo pasado, pero con modificaciones substanciales que las hacen diferentes entre si. (Cadena, 1996: 45) 
La vertiente más importante de esta teoría es la llamada corriente monetarista. El principal inspirador de dicha corriente, es el norteamericano Milton Friedman, quien por cierto fue premiado con el Nobel de Economía.

Para los monetaristas, el problema principal es controlar la demanda de dinero, la cuál se compone del nivel de precios, tasas de rendimiento de bonos y acciones, tasa esperada de inflación, la riqueza total, así como gustos y preferencias de los individuos. (Cadena, 1996: 46)

Según esta teoría, la oferta monetaria y la inflación, no reflejan necesariamente un aumento en la producción real. Si crece el circulante la inflación aumenta, lo que no sucederá con el volumen de mercancías producidas en una economía determinada. Con lo cuál, la producción de circulante es nocivo.

Lo anterior es argumento propuesto, contra el postulado keynesiano, en el sentido de aumentar circulante en la economía con el objeto de incentivar la producción. Consecuentemente, una de las luchas del nuevo liberalismo es, en contra del fenómeno inflacionario.

Otro de los supuestos básicos de la teoría neo liberal es, que "el desempleo juega un papel de ajuste estructural, ya que cuando la tasa de desocupados tiene un nivel "correcto", la inflación permanecerá estable". Por lo tanto, el desempleo es un fenómeno económico "natural" y no existen razones justificables para que el Estado intervenga en este sentido. (Cadena, 1996: 47)

Podemos ver entonces, que el nuevo liberalismo mexicano afirma y reconoce de manera abierta, la necesidad de la existencia del desempleo, como una de los supuestos básicos del nuevo modelo de acumulación. La ganancia puede y debe incrementarse a costa del destino de hombres y mujeres de cualquier sociedad.

\section{2. - Las Falacias Monetaristas}

El neoliberalismo en su corriente monetarista, considera como problema central de toda economía, el combate a la inflación y no el pleno empleo y la concentración del ingreso, como para los keynesianos. El Estado debe entonces, intervenir de una manera automática y no discrecional.

En la teoría keynesiana, el Estado aumentaba la oferta monetaria de manera voluntarista en el supuesto afán de incentivar la producción y el empleo. Lo anterior constituye un error según los monetaristas. El estado solamente debe hacer crecer la oferta monetaria de acuerdo al crecimiento del producto y a un nivel deseable de incremento de los precios. Podemos destacar, siguiendo a Edel Cadena, que uno de los supuestos de carácter ideológico de la teoría monetarista se centra en la ineficiencia intrínseca del aparato estatal. 
Según Friedman, el aumento del papel del Estado en la economía ha ido muy lejos en los últimos cincuenta años y ha representado altos costos en términos económicos. La intervención del Estado impone limitaciones a la libertad económica y amenaza con "liquidar dos siglos de progreso económico". (Cfr. Cadena, 1996: 50)

Tales afirmaciones tienen poca razón de ser. Esto por varias razones. La primera de ellas es, que nada nos puede llevar a afirmar de manera consistente, que el Estado sea un ente intrínsecamente ineficiente porque:

La ineficiencia es, en todo caso, un asunto de organización y de objetivos que pueden ser modificados racionalmente. Más aún, la forma de organización puede resultar ineficiente en cualquier tipo de estructura, pública o privada, si es que no hay necesidades fundamentales que la lleven a modificarse. Y por ello, si bien es cierto que la competencia económica es un acicate para la eficiencia, también es cierto que la monopolización o el establecimiento de oligopolios en muchas de las ramas de las empresas privadas las llevan a la ineficiencia. (Cadena, 1996: 50)

Es a partir de la acción estatal y gracias a ella, que los empresarios mexicanos pudieron impulsar la industrialización mexicana; ampliar la base productiva; generar empleos; aumentar las tasas de ganancia y amasar grandes fortunas personales antes de que el modelo se agotara. Una de las razones de la ineficiencia de la planta productiva mexicana actual por ejemplo, se debe, como se apunta líneas más arriba, a la incapacidad crónica de los empresarios mexicanos, para adecuarse a condiciones de competencia internacional.

Otro de los supuestos neo liberales, es de suyo, una falacia:

Parte del hecho, de que la riqueza privada al final de cuentas, se distribuye en el conjunto de la sociedad, es decir, que el crecimiento de las empresas privadas, generan posibilidades de beneficio colectivo. Esto no es claro, dado que: "...no hay mecanismos legales en una economía de mercado que obliguen a redistribuir el ingreso, si es que suponemos que los impuestos deben tender a disminuir. ¿Bajo qué mecanismo, si no es los impuestos, la riqueza se distribuye?” (Cadena, 1996: 51)

\section{3.- La desindustrialización mexicana}

La profundización de las políticas neoliberales en México, resultaron contrarias a lo que en teoría intentaron solucionar. Se suponía que la planta productiva se haría eficiente, que el país ingresaría a un nuevo estadio cercano o parecido, al del llamado primer mundo. Los resultados fueron distintos. Se muestran en el cuadro anexo, algunos datos que indican la tendencia en la formación del capital fijo en México. 
Podemos observar, que en los catorce años presentados, no existe periodo en el que se supere de manera sustancial la inversión de capital fijo. A partir de lo anterior, se puede afirmar, que las ganancias de los inversionistas se destinan a rubros diferentes a la formación de capital fijo. Dicho de otra forma: el capital resultante de las diversas actividades económicas, no se destinan a inversión productiva.

Es así, como podemos explicar el aumento en las operaciones del mercado financiero mexicano, el que tiene el honor de tener el mayor crecimiento porcentual de la historia del mundo financiero, con un $692 \%$ en octubre de 1987. (Cadena, 1996: 70)

El auge del mercado financiero indica, entre otras cosas, que las políticas públicas con orientaciones monetaristas, benefician la especulación en detrimento de la inversión productiva. Hoy, la economía mexicana tiene una orientación especulativa y no productiva. Es presa fácil de la fuga de capitales y el consumo de los capitalistas es básicamente suntuario. La mayoría de la planta productiva se encuentra en receso o trabajando con porcentajes de operación mínimos.

\section{Conclusión}

Los mecanismos más importantes que se instrumentan en la fase de industrialización mexicana, a partir de la posguerra y que permiten la concentración de recursos sociales para el desarrollo del sector industrial son como sigue:

a).- Política fiscal y de gasto público.

b).- Política de comercio exterior.

c).- Política de tipo de cambio.

d).- Política laboral.

Estas políticas, son las que impulsan el crecimiento y desarrollo de la planta industrial mexicana. Sin embargo, son los mecanismos que a la larga se convertirán en lastre, para la posibilidad del posterior perfeccionamiento de la planta industrial y sus procesos. Las políticas en cuestión, contenían elementos de efectivo impulso, tanto al crecimiento, como para el desarrollo, pero también, sus propias limitaciones.

La política fiscal preferencial y la inversión pública, fueron mecanismos importantes para la canalización de recursos al sector industrial. El crecimiento acelerado lo justificaba. No se trataba únicamente de inversión pública en infraestructura, sino también el amplio esfuerzo del Estado Mexicano para la educación de la fuerza de trabajo. Con ello se establecen 
una serie de condiciones, mínimas si se quiere, pero con resultados positivos. Sin embargo, la política fiscal y la inversión estatal dirigida hacia la industria, tuvo sus costos, tales como: la limitación en la inversión en otros sectores, como el agrícola, que ocupaba el 63\% de la PEA en los años cuarenta. (Trejo, 187:33)

La política de comercio exterior, tuvo efectos perniciosos principalmente sobre los precios. Los consumidores pagaron durante todo este tiempo, altos precios por los productos de manufactura nacional. Uno de los tantos objetivos de esta política en particular, era el de mantener altas tasas de ganancia, pero se financiaban la incompetencia, así como bajos niveles de eficiencia.

Los beneficios de las políticas de proteccionismo, si bien es cierto, permitieron un avance en la expansión industrial, generó una visión estrecha de una parte importante del empresariado mexicano, protegido de la' competencia externa y evitó en mucho, la dinamización y desarrollo de proyectos de innovación e incorporación, tanto de tecnología, como de formas de organización del trabajo.

En el marco de las políticas de cambio, la sobrevaluación del tipo de cambio, penalizaba a los sectores exportadores y abarataba, las exportaciones. Los beneficiarios de estas políticas, fueron sectores de la industria que podían efectuar importaciones con mayor facilidad y menor costo. No obstante, las importaciones fueron, casi en términos generales, en maquinaria, equipo, bienes intermedios, así como materias primas para la elaboración de productos manufacturados. Es así, como el sector industrial se benefició como vendedor en un mercado protegido, pero también como importador, que recibe sus divisas a un precio inferior, tanto por su valor de equilibrio, como por su costo social. La transferencia intersectorial de recursos que de esto resulta, es particularmente importante para México, dado que la industria es un sector mayoritariamente importador, en tanto que, la agricultura, la minería y el petróleo, han sido de manera tradicional, sectores generadores de divisas.

En cuanto a la política laboral, se puede decir que las modernas empresas industriales mexicanas, pagaban salarios considerablemente más elevados, que otras actividades laborales más tradicionales. Pero a diferencia de lo sucedido en países avanzados, los niveles de los salarios no permitieron que el trabajador industrial, fuera un consumidor importante de la producción de dicho sector. Lo que se observa es, que la participación de los salarios en el valor agregado total es muy inferior a la de los países avanzados, a la vez que las tasas de rentabilidad sobre el capital invertido es por lo regular, mucho mayor que en los citados países. 
La promesa de que la prosperidad llegaría con el crecimiento industrial, quedó a medias. Por encima de los objetivos de la política social, quedó siempre, la obtención de altas tasas de ganancia. Sin embargo, la política económica, generó un aumento en el consumo de la población a partir de la posibilidad del empleo. Aún en un esquema considerado incompleto o débil.

El Estado Mexicano, en términos políticos, no tenía muchos problemas de gobernabilidad. Existía una legitimidad tácita. La economía nacional sí tenía expectativas a corto y mediano plazo si las políticas de reconversión hubieran sido menos destructivas. El sector industrial había crecido y tal vez necesitaba una reconversión paulatina, haciendo énfasis en la superación, tanto de los atrasos tecnológicos, como de organización y flexibilización de la mano de obra. El mercado interno no debió abandonarse de la manera tan violenta como se llevó a efecto. La integración paulatina al mercado internacional, de una u otra forma, terminaría por hacer eficientes a las empresas nacionales, en la medida en que se fueran enfrentando a un mercado competitivo. Lo que se había logrado en más de cuarenta años, contenía un potencial que fue destruido por la irrupción de un capitalismo salvaje, paradójicamente lidereado por un "Nuevo Estado Mexicano".

Ante estas redefiniciones de importancia histórica, se hace necesario determinar las dimensiones de los cambios ocurridos. Éstos no son únicamente de carácter económico y social, sino que involucran un cambio en la naturaleza misma de nuestra sociedad. Una de las cuestiones que están hoy en la mesa de las discusiones, es la afirmación hecha por en nuevo discurso del poder, que plantea la llegada del neo liberalismo para no irse jamás. ¿Pruebas? Ahí está la "globalización” que pretende y elogra? la eficiencia económica. El nuevo orden se establece bajo el camuflaje de la "Democracia" y la "sociedad tolerante".

No obstante, ahí están también algunas cifras que demuestran lo contrario: concentración sin precedentes de la riqueza; masas empobrecidas y/o miserables; desempleo y subempleo. En suma: una masa gigantesca de condenados.

La reconversión de la industria y de la economía en México, se planteó en los términos de salida histórica tanto para el Estado, como para los decididores internacionales. Pero eso no significaba que fuese la única. El carácter de la reconversión así planteada, lleva el virus de la imposición y de la incapacidad de comprender otras alternativas a partir de experiencias en otras economías nacionales. y tal vez en mayor medida, la incapacidad de comprender, que las fuerzas productivas nacionales, tenían mucho más potencial de lo que las propias élites aceptan. Hoy, la crisis agudizada parece no tener 
salidas para la mayoría de la población. "El Leviatán (...) se metamorfosea en la sociedad tecnocrática y oligopólica de los dueños del capital. (...) quizá ni la más sofisticada visión estatista (socialismo, fascismo) logró imaginar las consecuencias totalitarias de una teoría económica como el monetarismo..."

(Cadena, 1996: 53)

\section{Bibliografía}

Argüelles, Antonio y José Antonio Gómez Mandujano (Comps.), 1994: La competitividad de la industria mexicana frente a la concurrencia internacional, México: Fondo De Cultura Económica NAFINSA.

Arrieta Robles, Patricia, 1994 "Reestructuraciones tecnológicas de la economía internacional y algunas de sus implicaciones para el sistema productivo mexicano" en Antonio Argüelles y José Antonio Gómez Mandujano (Comps): la competitividad de la industria mexicana frente a la concurrencia internacional, México: Fondo De Cultura Económica NAFINSA

Cadena Vargas, Edel, 1996: Neoliberalismo y sindicalismo en México, Toluca Universidad Autónoma del Estado de México.

Haber, Stephen, 1992: Industria y subdesarrollo. La Industrialización de México, 18401940, Alianza Editorial, México.

Kern, Hort y Michael Schumann, 1988: El fin de la división del trabajo. Racionalización en la producción industrial: situación actual, determinación de las tendencias, Madrid: Ministerio de Trabajo y Seguridad Social.

Trejo Reyes, Saúl, 1987: El futuro de la politica industrial en México, México El Colegio de México. 